\title{
Learning retention in mathematics over consecutive weeks: Impact of motivated forgetting
}

\author{
Julius Valderama ${ }^{1}$, Jubert Oligo ${ }^{2}$ \\ ${ }^{1}$ College of Arts and Sciences, Nueva Vizcaya State University, Bayombong, Philippines \\ ${ }^{2}$ College of Teacher Education, Nueva Vizcaya State University, Bayombong, Philippines
}

\section{Article Info \\ Article history: \\ Received Jan 16, 2021 \\ Revised Aug 12, 2021 \\ Accepted Sep 9, 2021 \\ Keywords: \\ Amount of learning Mathematics model Motivated forgetting Retention rate Time-series design}

\begin{abstract}
Retention is the ability to retain information in the mind, either in short-term or long-term memory. Memory in the long-term is more ideal. Thus, this has become a challenge for educators on how to transfer ideas in short-term memory to long-term memory. To concretize the effect of time on mathematics learning retention, a randomized pre-test post-test $\mathrm{x}$ groups design, using matched subjects was used in the study. Seven matched groups of students were identified, and took the pre-test as the basis of the initial amount of learning, after which a group of students was assigned to take the post-test every week for seven weeks. The post-tests results were the basis of the amount of retained learning of the students. The study found out that: i) The amount of retained learning among the students diminished following a negative exponential curve; ii) The amount of retained learning was comparably equal with the initial amount of learning up to the second week; iii) The amount of retained learning became incomparable with the initial amount of learning after the third week; and iv) The concepts in the knowledge level had a great chance to be remembered while the concept with analysis level was prone to motivated forgetting.
\end{abstract}

This is an open access article under the CC BY-SA license.

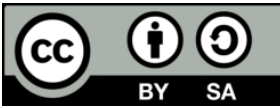

\section{Corresponding Author:}

Julius Valderama

Department of Mathematics and Statistics

Nueva Vizcaya State University

Bayombong, Nueva Vizcaya, Philippines

Email: valderamajulius@gmail.com

\section{INTRODUCTION}

The quality of mathematics education of each country in relation to other countries has been determined through international assessment. The result of such assessment has an impact on the national economy as documented in the World Economic Forum (WEF) with the Global Competitiveness Index (GCI) [1]. There are two leading large-scale international students' assessments which help each nation to evaluate their educational systems against other economies [2], [3]. The program results for international students assessment (PISA) is designed to assess students' preparedness for employment in future years, while the trends international mathematics and science survey (TIMSS) is a retrospective assessment whether learners have mastered what is taught. The PISA in 2018 and TIMSS in 2019 placed Filipino learners in disadvantaged positions. Filipino students ranked 77 out of 78 participating countries in PISA [4], and 58 out of 58 participating countries in TIMSS [5]. These reflect the position of the Filipino learners as to the level of mathematics literacy in the international context.

Looking back on previous international students' assessments, the Philippines was already prompted by the alarming situation that Filipino learners performed poorly in mathematics as compared to other 
countries [6]. Consequently, Filipino educators were on quests to find ways to resolve the problems on mathematics achievement. Thus, the government instituted initiatives such as the curriculum change to $\mathrm{k}-12$ curriculums, offering scholarships to mathematics educators, and giving additional incentives through salary leveling of the science and mathematics teachers. Educators were also in a continuing quest to find better ways of delivering a lecture, improving the teaching-learning process, designing instructional materials, and aligning the learning contents with the international assessment.

The National Assessment Test (NAT) of the Department of Education is an internal students' assessment of the country aimed to monitor the level of students' mathematics, science, and reading literacy. Scores of students provide a quick glimpse of the current state of education and among the seven subjects tested, mathematics and sciences were the subjects performed poorly by Filipino learners, consistent from 2004 to the present [7].

All of these initiatives hope that Filipino achievement in mathematics will be improved. However, despite these efforts, the latest results of PISA 2018 and TIMSS 2019 revealed that problem in mathematics performance is still a problem. Unresolved throughout the country. Ideally, if learners can improve their learning retention, the mastery of the topics could be improved. Consequently, mathematics performance could be increased [8]-[10]. Thus, problems on mathematics performance could be resolved.

Retention is the ability to retain information in mind. It is the preservation of the after effects of experience and learning that makes recall or recognition possible [11]. In education, learning retention plays a vital role for a learner to successfully learn the concepts taught inside or outside the classroom. Choosing a teaching strategy that result in knowledge retention on the part of learners can be challenging for educators [12]. Retention is the cognitive information processing of the learner which involves understanding, information processing, and storing within memory [13]. Students remember what they have learned, whereas transfer requires students not only to remember but also to gain a conceptual understanding and be able to use what they have learned [14]. Mathematics is perceived as one of the most difficult subjects among the students particularly those who are not inclined to mathematics [15]. The nature of the subject involves conceptual, as well as procedural knowledge [16].

Both the PISA and TIMSS aimed to identify areas in mathematics where learners excel as well as areas where they flunked. The cognitive domain of the questions included in the TIMSS were knowing, applying, and reasoning [4]-[6]. While, the PISA standard problem requires reasoning, analysis, evaluation, creation, and problem-solving abilities [17], [18]. These two assessments stressed more on the cognitive domain which is classified into two: lower order thinking skills (LOTS) and higher order thinking skills (HOTS). The PISA and TIMSS gave more emphasis on the HOTS component and further to test the ability of learners to apply logic \& reasoning, analysis, evaluation \& creation, problem-solving, and judgment [19].

The importance of HOTS in learning mathematics so students can find new challenges [20], mastering mathematics well [21], as a basis for students' skills in problem-solving, reasoning, and mathematical communication [22]. Some research results show that there was a significant relationship between HOTS and student learning outcomes [23], [24].

According to Nelson [25], there are many ways of classifying the human mind and its ability to retain information. One of the most often used classifications is based on the duration of memory retention, specifically the sensory, short-term memory, and long-term memory. Short-term memory refers to recent memory and is usually only held for a very short time. Long-term memory, on the other hand, can be thought of as a database where all the information that one has have learned is kept. Sensory memory is conveyed through your senses of sight and sound, where you keep these "images" in your mind.

The goal of educators is how to transfer the short-term memory learned in the classroom and to be part of the long-term memory. With this goal, several ideas and researches were offered to the public such as the concept of the learning pyramid and the retention rate. These two ideas pertain to the amount of learning retained to the human mind in using the different teaching strategies.

National Training Laboratories (NTL) in Betel popularized the learning pyramid [26], [27] and that giving a lecture will ensure $5 \%$ of the learning be retained to the students, reading accounted for $10 \%$, audiovisual (25\%), demonstration (30\%), discussion (50\%), practice doing (75\%) and teaching other is $90 \%$. Accordingly, the learning retention rates for an individual were accounted as: see/hear-lecture (5\%), audiovisual $(25 \%)$, demonstration (30\%), group discussion (50\%), practice by doing $(75 \%)$, teaching other $(90 \%)$ and immediate application of the situation in real life if $90 \%$.

Ilie and Serban [28] laid some facts that the learning pyramid cannot guarantee like what material or topics is recalled, the age of the subjects, the delay between study and test, what were subjects instructed to do as they read, demonstrated, and taught, how was memory tested, and what subjects know about the to-beremembered material. John, et al. [29] also posted the idea that many students continue to feel uneasy about math, lack confidence in their math abilities, or struggle to understand the value that math provides and that they value mathematics less. In addition, they found out that students who wrote consistently positive turning 
point narratives on mathematics had higher valuing for mathematics, and conversely, students who wrote consistently negative turning point narratives on mathematics had lower valuing for mathematics. These types of students are prone to motivated forgetting.

The idea of motivated forgetting is elaborated by some researchers in previous studies [30]-[35]. Individuals who have negative experiences on learning a particular subject, or those with high anxiety towards the said subject, as well as those individuals who perceived that the particular subject has less use in their daily living, have high chances of forcing themselves to forget what they have learned in that subject. They quickly forget the course content after complete the course. This kind of forgetting is referred to as motivated forgetting and accordingly, this affects the learning retention of the students. The principle of memory loss due to time interval [36] could increase the chance of motivated forgetting. As experienced by most of the learners, time interval plays a vital factor for the individual to forget what he/she knows, especially when he/she is not frequently encountering the idea, process, place, or person.

Mathematics is a domain in which many people report a high degree of stress and reported as people's most hated subject in school [37] and this affects their attitude towards the subject [38], their learning retention [39], and consequently, the mathematics performance [40]. Thus, topics in mathematics subject have higher chances to motivated forgetting.

Previous studies [41], [42] stated that if a student has a positive attitude to mathematics, he/she will be interested in its teaching and learning. On contrary, students with negative attitudes in mathematics are less interested in the teaching and learning of mathematics. The experiences of this group of students with a negative attitude are the biggest factor that they tended to develop anxiety in mathematics. As consequence, students tend to resort to motivated forgetting. Motivated forgetting describes the active process of forgetting unpleasant memories that pose threats to one's identity, or state of mind that he/she tries to maintain [34].

Learning retention exists in the mathematics classroom as could be deduced from this statement of many educators "what the teachers discussed today in their mathematics classes could easily be forgotten by the students on their next discussion". With these ideas on learning retention, and in relation to PISA and TIMSS results, the researchers conceptualized this study mainly to answer the following questions: i) How fast the learning diminishes over intervals of seven weeks?; ii) What particular level of learning competencies was remembered or forgotten?

\section{RESEARCH METHOD}

The randomized pretest-posttest $\mathrm{x}$ groups design, using matched subjects was used in the study to observe the differences in the amount of retained learning from the initial time (week 0) to weekly intervals for seven weeks (week 1-7). In this study, the concept of pre-test and post-test was adopted to determine the changes in the amount of retained learning from week 0 against the weekly observations for seven weeks. Likewise, the study utilized seven matched groups.

As reflected in Figure 1, three intact classes of students enrolled in Analytic Geometry with more than 150 students were the target respondents. Purposive sampling was used in the study in order to come up with seven groups with equivalent mathematics performances. The seven groups consisted of 15 students each with equivalent mathematics performance was identified as the actual respondents. The procedure in coming up with seven matched groups.

i) The tentative grades in Analytic Geometry during the 1st and 2nd terms of the semester of the students in the three intact classes were obtained and used as the basis in distributing the respondents into groups.

ii) The tentative grades were arranged in descending order, thus student 1 had the highest score, followed by student 2 up to the last element.

iii) In every group of seven students starting from students 1-7, students were randomly distributed to the seven groups. After which, students 8-14 were randomly distributed into seven groups. This procedure was repeatedly performed until the last seven students were randomly distributed into the seven groups.

iv) Thus, creating seven groups of students with matched mathematics performance. The 15 students per group were the identified actual respondents of the study.

The teacher's class record in Analytic Geometry during the 1st term and 2nd term was used as the basis of the students' tentative grades. A pre-test instrument consisting of 46 items was designed to establish the benchmark data before the conduct of the research. The items included in the test were 17 definition level, 13 comprehension level, and 16 analysis level. All the items were taken from the teacher's question bank and were frequently included in the examinations. Further, these questions were validated, and later the Cronbach Alpha of 0.87 was established and at an acceptable level. Although, the questions in the post-test were the same as in the pre-test, the item placement as was well as its options was rearranged to remove or lessen the influence of test familiarity. 


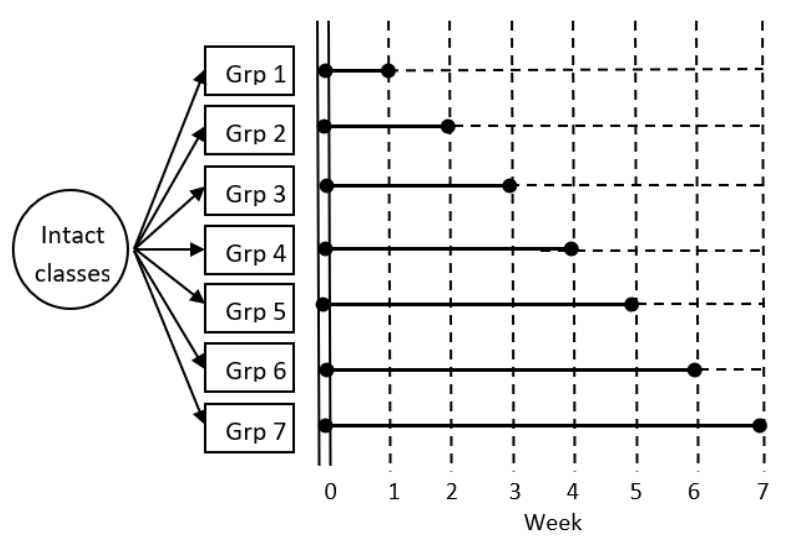

Figure 1. The paradigm of the study

The groups of student respondents were enrolled in Analytic Geometry, their terminal subject in mathematics. They also considered mathematics as one of the hated disciplines, they have a negative attitude towards it, and that they hardly see the importance or relevance of this subject to their course. Thus, these groups of students resemble the characteristics prone to motivated forgetting [29]-[35].

The identified seven matched groups had equivalent mathematics performance based on the students' tentative grades in Analytic Geometry. After the intact classes were divided into seven groups, all the respondents were subjected to the first and second pre-tests in week 0 . The second pre-test was administered a day after the first pre-test was conducted. Only the items answered by the respondents correctly in the first and second pre-testing were considered in the study. The items that were mistakenly answered by the respondents in the first pre-test but correctly answered in the second pre-test, or were correctly answered in the first pre-test and mistakenly answered in the second pre-test were not considered in the study. The pre-test scores of the students served as the initial amount of learning.

First post-test was conducted among the first group of respondents after week one; this was the basis of amount of learning retained after week one. The second post-test was conducted among the second group of respondents after week two; this was the basis of amount of learning retained after week two. The post-test was conducted repeating the procedure after the 3rd week, 4th week up to 7 th week. The post-test results were the basis of the amount of retained learning after the 3rd up to the 7th week.

The following statistical procedure was used in the study: means and standard deviations were used to describe the retained learnings of the students in every group; the rate of change was used to determine the amount of retained learning from the initial score; the amount of retained learning was computed by $100 \%$ rate of change; t-test correlated was employed to determine in what week intervals did significance in amount of retained learning were significantly different.

\section{RESULTS AND DISCUSSION}

\subsection{Mathematics performance of the respondents}

Table 1 reflects the performance of the respondents in each group in the pre-tests. The mean scores ranged from 16.73 to 17.07 , and the score intervals with the highest frequency were 7-13 and 14-20 points. The majority of the students in each group had a mathematics performance lower than the $50 \%$ of the total score. The mean scores and their location in the distribution suggest that the distribution of mathematics performance in each group was skewed to the right. Many students had performance scores lower than the average scores. In addition, the majority of the students had performance scores lower than $50 \%$ of the total items. This low performance of students in this basic mathematics also reflects the PISA 2019 results where Filipino students' mathematics performance was ranked at the bottom [4]. Thus, this could be inferred that the student-respondents had difficulty in Analytic Geometry or mathematics as a whole. Further, as described earlier, the characteristics of these groups of students were prone to motivated forgetting [29]-[35].

The computed F-value was 0.02 together with the significance value of 0.88 suggests that the mean scores of the seven groups of students during the pre-tests were statistically the same level. This implies that the students' groupings had the same level or comparable amount of initial mathematics learning before the conduct of the study. The result confirms that during the matched-up procedure, students in every group were correctly matched to other groups and that each group has equal mathematics ability compared to other groups. 
Table 1. The initial mathematics performance of the respondents in each group

\begin{tabular}{cccccccc}
\hline Score & Group 1 & Group 2 & Group 3 & Group 4 & Group 5 & Group 6 & Group 7 \\
\hline $0-6$ & $1(6 \%)$ & $1(6 \%)$ & $2(13 \%)$ & $0(0 \%)$ & $0(0 \%)$ & $1(6 \%)$ & $1(6 \%)$ \\
$7-13$ & $5(33 \%)$ & $5(33 \%)$ & $4(26 \%)$ & $6(40 \%)$ & $4(26 \%)$ & $5(33 \%)$ & $5(33 \%)$ \\
$14-20$ & $5(33 \%)$ & $4(26 \%)$ & $5(33 \%)$ & $5(33 \%)$ & $6(40 \%)$ & $6(40 \%)$ & $5(33 \%)$ \\
$21-27$ & $2(13 \%)$ & $3(20 \%)$ & $2(13 \%)$ & $2(13 \%)$ & $3(20 \%)$ & $1(6 \%)$ & $2(13 \%)$ \\
$28-34$ & $1(6 \%)$ & $1(6 \%)$ & $1(6 \%)$ & $1(6 \%)$ & $1(6 \%)$ & $1(6 \%)$ & $1(6 \%)$ \\
$35-41$ & $1(6 \%)$ & $1(6 \%)$ & $1(6 \%)$ & $1(6 \%)$ & $1(6 \%)$ & $1(6 \%)$ & $1(6 \%)$ \\
N & 15 & 15 & 15 & 15 & 15 & 15 & 15 \\
Mean & 17.00 & 16.93 & 16.80 & 17.07 & 16.73 & 16.93 & 16.80 \\
\hline F-value $=0.02 ;$ sig=0.88 & & & & &
\end{tabular}

The respondents of this study were students not incline to mathematics and they only took the subjects since it is a requirement for the completion of their undergraduate degree. The majority of them also had a somewhat negative attitude towards the subject, and just to mention, the subject tested in this study was their last mathematics course and has no prerequisite courses for their degree. The given situation goes in parallel with the cited reasons why students opted to motivated forgetting [34].

The researcher asked the respondents and tried to elicit justification why the students have poor performance in mathematics, and these were the common words brought by the students: frustrated, confused, negative, "so what", bored, and fearsome. These words were almost similar to the most frequently occurring emotions during a problem-solving activity [43], [44].

\subsection{Retention rate over seven weeks}

Table 2 reflects the mean scores of the respondents per group from week 1 to week 7 in the posttests, including the computed rates of change from the initial scores and post-tests, as well as the computed amount of retained learning per group. The initial value for the amount of learning of the student-respondents was measured during the pre-tests and the initial values of $100 \%$ were considered as the initial percentage of retained learning. This will be used as a reference for the amount of reduction of learning, as well as retained learning.

After one week, students had a 5.39\% decrease from the 17.00 initial mean score to 16.08 in the post-test. Thus, the amount of retained learning after one week was $94.61 \%$. After two weeks, the accounted decrease was $9.82 \%$ from the 16.93 initial mean scores to 15.27 post-test. Thus, the amount of retained learning after two weeks was $90.18 \%$. After week 3 to week 5, the accounted decrease from the initial mean scores were $13.54 \%$ for week $3,15.60 \%$ for week 4 , and 16.03 for week 5 with the corresponding amount of retained learning's of $86.46 \%, 84.40 \%$, and $83.97 \%$. After week 6 and week 7 , the accounted decreases were $20.66 \%$ and $21.94 \%$ with the amount of retained learning equivalent to $79.34 \%$ and $78.06 \%$, respectively.

Based on the results, the amount of retained learning from week 0 to week 7 gradually decreased up to $78 \%$ amount of retained learning. On average, the decrease in retained learning is accounted for at the rate of $3.0 \%$ per week. The decreasing pattern as to the retained learning which could be associated due to motivated forgetting was also the finding of previous study [45]. Research explained that forgetting is a function of the amount learned and the passage of time, not of the learning rate or other variables [46]. While, Ling [34] stated some possible reasons why students forget mathematics, such as if they feel stressed out by the math course, thought the course was not important, or they just did not care about the course.

Table 2. The mean scores of the respondents per group in the post-test, rate of change and the amount of retained learning

\begin{tabular}{ccccc}
\hline Group (i) & Pre-test (week 0) & Post-test (week i) & Rate of change (\%) & Amount of retained learning (\%) \\
\hline 1 & 17.00 & 16.08 & -5.39 & 94.61 \\
2 & 16.93 & 15.27 & -9.82 & 90.18 \\
3 & 16.80 & 14.53 & -13.54 & 86.46 \\
4 & 17.07 & 14.40 & -15.60 & 84.40 \\
5 & 16.73 & 14.05 & -16.03 & 83.97 \\
6 & 16.93 & 13.43 & -20.66 & 79.34 \\
7 & 16.80 & 13.11 & -21.94 & 78.06 \\
\hline
\end{tabular}

\subsection{The retention curve and differences between initial and retained learning over seven weeks}

There are theoretical arguments based on a geometrical analysis that explain the learning curve as well as the retention curve. Accordingly, the learning curve follows power functions [47], [48], or exponential functions [46], or similar to Ebbinghaus curve [49], [50]. Figure 2 reflects the mathematics retention curve and the comparison between the initial scores and post-test over the seven weeks. As depicted

Learning retention in mathematics over consecutive weeks: Impact of motivated ... (Julius Valderama) 
in Figure 2, mathematics learning decreased over seven weeks but a gradual decreased could be noted starting from week 6 and the succeeding week. The curve followed the negative exponential curve [46] and this was also fitted to describe the learning and forgetting curve. Hence, it could be inferred that amount of retained learning would not reach zero $(0)$ as it becomes asymptotic up to the possible minimum retained learning.

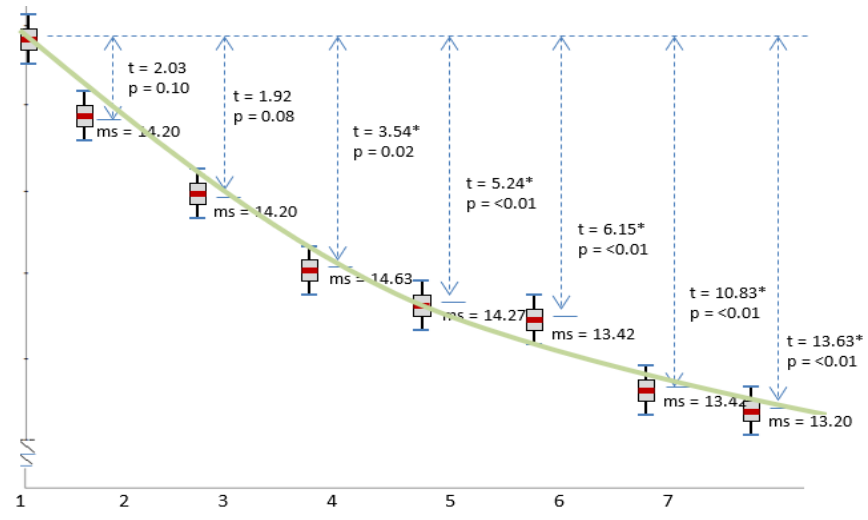

Figure 2. The retention curve

The retained learning scores of the seven groups during the pre-test ranged from 16.80 to 17.07. After weeks 1 and 2, the retained learning mean scores for group 1 was 16.00, and 15.25 for group 2. The retained learning mean scores after three weeks was 14.20, after four weeks was 14.63, after five weeks was 14.27, after six weeks was 13.42, and after seven weeks was 1.20.

The difference between the amount of retained learning as measured in the pre-test scores (week 0) and post-test scores during week 1 and week 2 were computed. The result revealed that there were no significant differences in retained learning mean scores after 1 st week and 2 nd week. These findings were based on the computed $t$ values together with the corresponding $\mathrm{p}$ values of $\mathrm{t}=2.03$ with $\mathrm{p}=0.10$ for week 1 , and $\mathrm{t}=1.92$ with $\mathrm{p}=0.08$ for week 2 . The results further suggest that statistically, students had the same amount of retained learning within two weeks.

According to the findings, after week 1 and week 2, the amount of learning retained are comparably equal to the initial amount of learning. It could be inferred from these findings that students could still recall topics that they have learned even after two weeks. Students can store and recall facts, concepts, and operations in mathematics even after two weeks without intervention or reviews. Although the graph illustrated a decreasing trend, the $p>0.05$ implies that it is comparably equal to the initial amount of learning.

Applying the concept of "Law of Recency", recent acts are lasting. Individuals remember things better which are recent. Hence, a learner should try to have some re-reading of the past lessons he/she took from the past two weeks in order not to forget or at least minimize the effect of forgetting. The difference between the amount of retained learning in the pre-tests (week 0) and post-test after three weeks (week 3 ) and succeeding weeks, from week 4 to week 7 and were found significantly different. These findings were based on the $\mathrm{t}=3.53$ with $\mathrm{p}=0.02$ for week $3, \mathrm{t}=5.24$ with $\mathrm{p}=<0.01$ for weeks $4, \mathrm{t}=6.15$ with $\mathrm{p}=<0.01$ for week 5 , $\mathrm{t}=10.83$ with $\mathrm{p}=<0.01$ for week 6 , and $\mathrm{t}=13.63$ with $\mathrm{p}=<0.01$ for week 7 . The results further suggest that after three weeks, the amount of retained learning were already significantly different and lesser than the initially gained learning score.

The results further imply that topics discussed with students particularly to groups of students who were prone to motivated forgetting start to weaken; the learning retention diminished, or motivated forgetting becomes apparent after three weeks from the last discussion. Teachers should schedule quizzes every after two weeks or perhaps to conduct a review class before the exam if the teacher plans to have a quiz after two weeks.

In this study, the concepts of learning decay [51] deal with the gradual effect of the individual's cognition over the period of time that explains the findings. Further, Ricker, Vergauwe, and Cowan [52] also made a remarkable statement that information is lost as a function of time. While, Geralda, Wolters, and Giezen [53] stated that longer retention intervals before initial testing could result in lower accuracy and lower confidence scores. Gerardo [54] stated that students commonly engage in forgetting when their selves interpreted that what they encountered is no longer relevant. 


\subsection{Amount of retained learning over seven weeks as to the learning competencies}

The amount of retained learning as to the learning competencies from week 0 to week 7 is reflected in Figure 3 particularly: Figure 3(a) definition/knowledge level; Figure 3(b) comprehension level; and Figure 3(c) application/analysis level. The established linear regression of the amount of retained learning for definition/knowledge level was $y=-0.0409 x+5.8726$. The trend line indicates that retained learning reduced gradually from week 1 up to week 7 . The slope -0.04 suggests that on average, the estimated reduction of the amount of retained learning for definition/knowledge level was a $4 \%$ reduction for every week. If an individual would wish to improve the trend line and make it more gradual, manipulation of prior experiences may be considered to alter the impact of forgetting [55].

The established linear regression of the amount of learning for comprehension level was $y=-0.1712 x+5.3426$. The trend line indicates that the retained learning reduced gradually from week 1 up to week 7 . The slope -0.17 suggests that on average, the estimated reduction in the amount of retained learning for comprehension level was a $17 \%$ reduction for every week. The established linear regression of the amount of retained learning for application/analysis was $y=-0.2145 x+4.9217$. The trend line indicates that retained learning reduced gradually from week one up to week 7 . The slope -0.21 suggests that on average, the estimated reduction in the amount of retained learning for comprehension level was a $21 \%$ reduction for every week.

The slopes in the three figures suggest that students tend to forget learning. Topics or concepts classified as an analysis/application levels forget learning at a faster rate than the learning's in the definition/knowledge and comprehension levels. These conclusions were based on the slopes of -0.21 for analysis/application levels, which had a higher absolute value compared to the absolute value of the slopes 0.04 for definition/knowledge levels, and -0.17 for comprehension level. The slopes also imply that retained learning classified as analysis/application levels were mostly retained over the seven weeks than the learning's classified as comprehension or analysis/application levels.

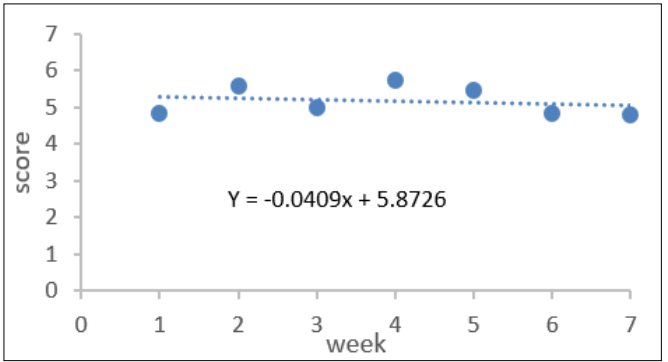

(a)

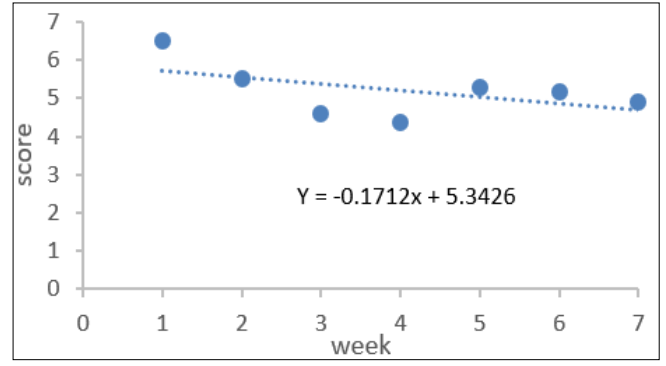

(b)

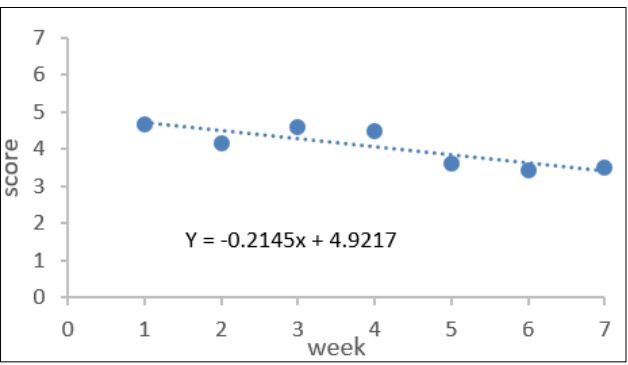

(c)

Figure 3. The amount of retained learning over the seven weeks as to the learning competencies:

(a) definition level; (b) comprehension level; and (c) analysis/application level

The differences as to the amount of learning retained when responses were categorized according to levels of skill could be explained by Codding, et al. [56]. Accordingly, student performance as well as the learning retention on topics involving more complex computational skills such as word problems that need analysis and application were directly related to the arithmetic skills of the students. Nonmanut, et al. [57] expounded that the mathematics word problem-solving skills is affected if students are poor at applying number properties, required operations, and number-solving steps. Mastery of procedural skills affects the students' mathematics performance [58]. 
The estimated intercepts of 5.8726 for definition/knowledge levels, 5.3426 for comprehension level, and 4.9217 for analysis/application levels suggest that on the average, the biggest portion of the retained learnings during week 0 were accounted from the definition/knowledge levels, followed by the comprehension level, and the analysis/application levels. These further imply that even in week 0 or just after the topic discussion, learnings classified as definition/knowledge level were easily stored and gradually diminished over seven weeks. On the contrary, learnings classified as analysis/application levels were not easily stored in the memory as compared to learnings in the definition/knowledge levels, and that these learnings had a higher chance to be diminished over seven weeks.

From the results, students tend to forget topics that were classified as difficult or topics that involved analysis or application level, as compared to topics classified as the definition or knowledge level. Students had difficulty in answering topics that require analysis or application as a result; they tend to get low scores on these topics during the examination. The impact of motivated forgetting was very apparent to this group of students.

The TIMSS uses a four-part skills categorization: knowing facts and procedures, using concepts, solving routine problems, and mathematical reasoning. These categories are ordered so that, "in general, the cognitive complexity of tasks increases from one broad cognitive domain to the next" [5]. Similar to the results, topics exhibited by skills category knowing facts and procedure, have high chances to be retained after seven consecutive weeks, as compared to topics exhibited by skill category problem solving, and reasoning with the low chances to be retained. Adopting the idea of Tibbles [59], "the impact of forgetting of prerequisite skill learning," could explain the result that topics requiring higher skills could be easily forgotten as compared to topics requiring lower skills. On the other hand, Choffin, et al. [60] worked on modeling the student learning and forgetting to optimally distribute and schedule series of practices of skills.

\section{CONCLUSION}

The amount of retained learning in Mathematics among the students was gradually diminished over seven consecutive weeks at the rate of $3.0 \%$ per week, and on average, the retained learning was accounted for $78 \%$ after the seventh week. Thus, teachers should plan or design to give quizzes as frequently as weekly or every two weeks.

No significant difference in the amount of gained learnings and retained learnings from week 0 to week 2, while a significant decrease in the amount of retained learnings from the gained learnings was established starting from week 3 to week 7 . Thus, a teacher may conduct review classes for all topics covered for the past three weeks to minimize the effect of motivated forgetting and increase learning retention. If the teacher intends to give quizzes with topics coverage of more than two weeks, a teacher may conduct review classes before executing the quiz for the students to recall the topics.

The amount of retained learnings decreased for concepts or topics in the definition/knowledge level at average rate of $4 \%$ every week, up to $17 \%$ per week decrease for concepts or topics in the comprehension level, and up to $21 \%$ every week decrease for concepts or topics in the application/analysis level. Hence, teachers should design the examination properly by preparing the corresponding table of specification to ensure that the test will consist of questions in knowledge, comprehension, and analysis levels

\section{REFERENCES}

[1] T. S. Nababan, "Development analysis of global competitiveness index of ASEAN-7 countries and its relationship on gross domestic product," Integrated Journal of Business and Economics, Vol. 3, No. 1, pp. 1-14, 2019.

[2] S. Sellar, G. Thompson, and D. Rutkowski, The global education race: Taking the measure of PISA and international testing. Brush Education, 2017.

[3] C. E. Laura, D. Rutkowski, and G. Thompson, "Toward an international measure of global competence? A critical look at the PISA 2018 framework," Globalisation, Societies and Education, vol. 17, no. 2, pp. 117-131, 2019.

[4] Organisation for Economic Cooperation and Development (OECD), 21st-Century Readers: Developing Literacy Skills in a Digital World. OECD Publishing, Paris, 2021, doi: 10.1787/a83d84cb-en.

[5] I. V. S. Mullis, M. O. Martin, P. Foy, D. L. Kelly, and B. Fishbein "TIMSS 2019 International Results in Mathematics and Science," Boston College, TIMSS and PIRLS International Study Center, 2020. [Online]. Available: https://timssandpirls.bc.edu/timss2019/international-results.

[6] M. U. Balagtas, D. C. B. Garcia, and D. C. Ngo, "Looking through Philippine's K to 12 Curriculum in Mathematics and Science vis-a-vis TIMSS 2015 Assessment Framework," EURASIA Journal of Mathematics, Science and Technology Education, vol. 15, no. 12, pp. 1-14, 2019, doi: 10.29333/ejmste/108494.

[7] Philippines Department of Education (DepED RO2). 2018 National Achievement Test (NAT) 6,10 \& 12 Results and Analysis, 2019. [Online]. Available: http://region2.deped.gov.ph/urm-s-20192018-national-achievement-testnat-610-12-results-and-analysis. 
[8] Y. T. Madu. "Mastery Learning Approach (MLA): Its Effects on The Students Mathematics Academic Achievement," European Journal of Alternative Education Studies, vol. 3, no. 1, pp. 77-88, 2018, doi: 10.5281/zenodo. 1227280 .

[9] T. Lubna, A. Ali, and F. Jabeen, "The effect of mastery learning strategy on learning retention of secondary school students in the subject of mathematics," Journal of Education and Practice, vol. 8, no. 19, pp. 46-51, 2017.

[10] T. Lubna and A. Ali, "Effects of Mastery Learning Model on Academic Achievement of Secondary School Students in Mathematics," Global Social Science Review, vol. 4, no. 4, pp. 232-238, 2019.

[11] E. S. Ahlam and H. Gaber, "Impact of problem-based learning on students critical thinking dispositions, knowledge acquisition and retention," Journal of Education and Practice, vol. 5, no. 14, pp. 74-83, 2014.

[12] S. Roya, M. M. Sedaghat, and F. S. Ahmadi, "Comparison of the effect of lecture and blended teaching methods on students' learning and satisfaction," Journal of Advances in Medical Education and Professionalism, vol. 2, no. 4, pp. 146-150, 2014.

[13] S. T. Lutz and W. G. Huitt, "Information Processing and Memory: Theory and Applications," in W. Huitt, Ed., Becoming a Brilliant Star: Twelve core ideas supporting holistic education. La Vergne, TN: IngramSpark, 2018, pp. 25-43.

[14] R. Paul and L. Elder, Critical thinking: Tools for taking charge of your learning and your life. Pearson, 2020.

[15] K. Anu, M. Vauras, and R. Kinnunen, "Instructing low-achievers in mathematical word problem solving," Scandinavian Journal of Educational Research, vol. 54, no. 4, pp. 335-355, 2010.

[16] B. Rittle-Johnson and M. Schneider, "Developing conceptual and procedural knowledge of mathematics," in Oxford Handbook of Numerical Cognition, 2015, pp. 1118-1134, doi: 10.1093/oxfordhb/9780199642342.013.014.

[17] H. Setiawan "Mathematic questions in PISA relation to mathematics literacy and high order thinking skills," (in Indonesia), Proceedings of the National Mathematics Colloquium, Universitas Jember, 2014, pp. 244-251.

[18] D. Kurniati and A. M. Annizar, "The analysis of students' cognitive problem solving skill in solving PISA standard-based test item," Advanced Science Letters, vol. 23, no. 2, pp. 776-780, 2017, doi: 10.1166/asl.2017.7466.

[19] Y. M. Heong, W. Othman, J. Md Yunos, T. T. Kiong, R. Hassan, and M. M. Mohamad "The level of Marzano higher order thinking skills among technical education students," International Journal of Social Science and Humanity, vol. 1, no. 2, pp. 121-125, 2011, doi: 10.7763/IJSSH.2011.V1.20.

[20] R. Amalia, "The application of model for proving to increase high order mathematical thinking ability of senior high school students," (in Indonesia), Thesis, Universitas Pendidikan Indonesia, 2013.

[21] M. Aleksius, "Higher Order Thinking Skills (HOTS) In Math Learning," IOSR Journal of Mathematics (IOSR$J M$ ), vol. 13 , no. 5 , pp. $70-75,2017$.

[22] T. Widodo and S. Kadarwati "Problem-solving-based higher order thinking to improve learning achievement through students' character building orientation," (in Indonesia), Cakrawala Pendidikan, no. 1, pp. 161-171, 2013, doi: $10.21831 /$ cp.v5i1.1269.

[23] B. Tanujaya, J. Mumu, and G. Margono "The Relationship between higher order thinking skills and academic performance of student in mathematics instruction," International Education Studies, vol. 10, no. 11, pp. 78-84, 2017.

[24] J. Jailani, S. Sugiman, and E. Apino "Implementing the problem-based learning in order to improve the students' hots and characters," (in Indonesia), Journal of Mathematic Education Research, vol. 4, no. 2, pp. 247-259, 2017.

[25] C. Nelson, "The many faces of working memory and short-term storage," Psychonomic Bulletin and Review, vol. 24, no. 4, pp. 1158-1170, 2017.

[26] K. Letrud, “A Rebuttal of NTL Institute's Learning Pyramid,” Education, vol. 133, no. 1, pp. 117-124, 2012.

[27] J. Yanling and X. Tong, "Learning pyramid theory in the application and practice of flipped classroom," China Educational Technology, vol. 7, pp. 133-138, 2014.

[28] G. C. Ilie and I. Serban, "Methods used in the Educational Process: A theoretical and empirical perspective," International Journal of Academic Research in Business and Social Sciences, vol. 8, no. 4, pp. 416-430, 2018.

[29] J. E. John, P. A. Nelson, B. Klenczar, and R. D. Robnett, "Memories of math: Narrative predictors of math affect, math motivation, and future math plans," Contemporary Educational Psychology, vol. 60, Jan. 2020, doi: 10.1016/j.cedpsych.2020.101838.

[30] K. Kogan, F. El Ouardighi, A. Herbon, "Production with learning and forgetting in a competitive environment," International Journal of Production Economics, vol. 189, pp. 52-62, 2017, doi: 10.1016/j.ijpe.2017.04.008.

[31] D.H. Groome, M. W. Eysenck, and R. Law, "Motivated forgetting: forgetting what we want to forget," in M.W. Eysenck and D.H. Groome, ed., Forgetting: Explaining Memory Failure. Sage, 2020, pp. 147-168.

[32] A. N. Dalton and L. Huang. "Motivated forgetting in response to social identity threat," Journal of Consumer Research, vol. 40, no. 6, pp. 1017-1038, 2014.

[33] A. P. DePrince, et al. "Motivated forgetting and misremember: Perspectives from betrayal trauma theory," in R. F. Belli, Ed., True and false recovered memories: Toward a reconciliation of the debate. Springer Science + Business Media, 2012, pp. 193-242, doi: 10.1007/978-1-4614-1195-6_7.

[34] J. Ling, "Are Students Motivated to Forget Math?" Master Thesis, University of California, United States, 2016. [Online]. Available: https://escholarship.org/uc/item/3jj1t5hp.

[35] K. N. Rotella and J. A. Richeson, "Motivated to "forget" the effects of in-group wrongdoing on memory and collective guilt," Social Psychological and Personality Science, vol. 4, no. 6, pp. 730-737, 2013

[36] D. H. Schunk, Learning theories: An educational perspective, 6th ed. Pearson, 2012.

[37] P. Peng, M. Barnes, J. Namkung, and C. Sun "A meta-analysis of mathematics and working memory: Moderating effects of working memory domain, type of mathematics skill, and sample characteristics," Journal of Educational Psychology, vol. 108, no. 4, 2016, doi: 10.1037/edu0000079. 
[38] M. Vandecandelaere, S. Speybroeck, G. Vanlaar, B. De Fraine, and J. V. Damme "Learning environment and students' mathematics attitude," Studies in Educational Evaluation, vol. 38, no. 3-4, pp. 107-120, 2012.

[39] S. Tou, W. Tou, D. Mah, A Karatassas, and P Hewett, "Effect of preoperative two-dimensional animation information on perioperative anxiety and knowledge retention in patients undergoing bowel surgery: a randomized pilot study," Colorectal Disease, vol. 15, no. 5, pp. e256-e265, 2013, doi: 10.1111/codi.12152.

[40] D. Amy, K. F. Williams, D. Szücs, and A. Dowker, "Gender differences in mathematics anxiety and the relation to mathematics performance while controlling for test anxiety," Behavioral and Brain Functions, vol. 8, no. 1, pp. 1-9, 2012, doi: 10.1186/1744-9081-8-33.

[41] A. Telima, "Problems of teaching and learning of geometry in secondary schools in Rivers State, Nigeria," International Journal of Emerging Sciences, vol. 1, no. 2, pp. 143-152, 2011.

[42] R. W. Gimba, A. M. Hassan, A. A. Yaki, and A. M. Chado, "Teachers' and Students' Perceptions on the Problems of Effective Teaching and Learning of Science and Technology in Junior Secondary Schools," Malaysian Online Journal of Educational Sciences, vol. 6, no. 1, pp. 34-42, 2018.

[43] I. Di Leo, K. R. Muis, C. A.Singh, and C. Psaradelliset, "Curiosity... Confusion? Frustration! The role and sequencing of emotions during mathematics problem solving," Contemporary Educational Psychology, vol. 58, pp. 121-137, Jul. 2019, doi: 10.1016/j.cedpsych.2019.03.001.

[44] K. L. Boehme, T. Goetz, and F. Preckel, "Is it good to value math? Investigating mothers' impact on their children's test anxiety based on control-value theory," Contemporary Educational Psychology, vol. 51, pp. 11-21, 2017, doi: 10.1016/j.cedpsych.2017.05.002.

[45] J. S. Fisher and G. A. Radvansky, "Linear forgetting," Journal of Memory and Language, vol. 108, 2019, doi: 10.1016/j.jml.2019.104035.

[46] E.J.F.M. Custers and O.T.J. Ten Cate, "Very long-term retention of basic science knowledge in doctors after graduation," Medical Education, vol. 45, no. 4, pp. 422-430, 2011, doi: 10.1111/j.1365-2923.2010.03889.x.

[47] J.M.J. Murre and A.G. Chessa, "Power laws from individual differences in learning and forgetting: mathematical analyses," Psychonomic Bulletin and Review, vol. 18, no. 3, pp. 592-597, 2011, doi: 10.3758/s13423-011-0076-y.

[48] A. Lee and A. Heathcote, "The form of the forgetting curve and the fate of memories," Journal of Mathematical Psychology, vol. 55, no. 1, pp. 25-35, 2011, doi: 10.1016/j.jmp.2010.08.009.

[49] J.M.J. Murre and J. Dros, "Replication and analysis of Ebbinghaus' forgetting curve," PloS one, vol. 10, no. 7, 2015, doi: 10.1371/journal.pone.0120644.

[50] B. Subirana, A. Bagiati, and S. Sarma, "On the Forgetting of College Academic: at "Ebbinghaus Speed"?" 9th International Conference on Education and New Learning Technologies, 2017, doi: 10.21125/edulearn.2017.0672.

[51] N. E. Spear, The Processing of Memories (PLE: Memory): Forgetting and Retention. Psychology Press, 2014.

[52] T. J. Ricker, E. Vergauwe, and N. Cowan, "Decay theory of immediate memory: From Brown (1958) to today (2014)," Quarterly Journal of Experimental Psychology, vol. 69, no. 10, pp. 1969-1995, 2016, doi: 10.1080/17470218.2014.914546.

[53] O. Geralda, G. Wolters, and A. van Giezen, "Accuracy, confidence and consistency in repeated recall of events," Psychology, Crime and Law, vol. 19, no. 7, pp. 629-642, 2013, doi: 10.1080/1068316X.2012.660152.

[54] R. Gerardo, "Motivated forgetting in early mathematics: A proof-of-concept study," Frontiers in Psychology, vol. 8, 2017, doi: 10.3389/fpsyg.2017.02087.

[55] I. van Stiphout, P. Drijver, and K.Gravemeijer, "The development of algebraic proficiency," International Electronic Journal of Mathematics Education, vol. 8, no. 2-3, pp. 62-80, 2011.

[56] R. Codding, S. H. Mercer, J. E. Connell, and C. A. Fiorell, "Mapping the relationships among basic facts, concepts and application, and common core curriculum-based mathematics measures," School Psychology Review, vol. 45, no. 1, pp. 19-38, 2016, doi: 10.17105/SPR45-1.19-38.

[57] P. Nonmanut, A. Kajamies, K. Veermans, K. Lertola, M. Vauras, and E. Lehtinen, "What makes mathematical word problem solving challenging? Exploring the roles of word problem characteristics, text comprehension, and arithmetic skills," ZDM: Mathematics Education, vol. 52, pp. 33-34, 2020, doi: 10.1007/s11858-019-01118-9.

[58] L. Shmuelof, V. S. Huang, A. M. Haith, R. J. Delnicki, P. Mazzoni, and J. W. Krakauer, "Overcoming motor "forgetting" through reinforcement of learned actions," J. Neuroscience, vol. 32, no. 42, pp. 14617-14621a, 2012, doi: 10.1523/JNEUROSCI.2184-12.2012.

[59] R. Tibbles, "Fractional Recall: Understanding Forgetting of Mathematics Learning from Computer Assisted Instruction Data and Implications for Personalized Learning in Low Resource Contexts," Dissertation, University of California, San Diego, United States, 2017.

[60] B. Choffin, F. Popineau, Y. Bourda, and J.-J. Vie, "DAS3H: modeling student learning and forgetting for optimally scheduling distributed practice of skills," arXiv, 2019. [Online]. Available: https://arxiv.org/abs/1905.06873. 